\title{
As "crianças da zika" segundo nos contaram os jornais brasileiros: uma leitura retrospectiva a partir da cobertura noticiosa $^{1}$
}

\author{
Alessandra Santana Soares e BARROS ${ }^{2}$
}

\begin{abstract}
Resumo:
Parte-se da premissa de que a epidemia de Zika seria uma história não acabada, na medida em que suas consequências se estenderão para sempre. Estão estampadas nas sequelas sofridas pelas crianças acometidas pela síndrome congênita - deficientes múltiplos, que seguirão demandando, de suas famílias e do Estado, cuidados perenes. Desse modo, foi encaminhada uma pesquisa documental que analisou a narrativa de jornais brasileiros de grande circulação sobre a Síndrome Congênita do Zika-Vírus/Microcefalia, recortada ao longo dos dois e meio primeiros anos da cobertura noticiosa. Interessava saber como se deu o enquadramento discursivo acerca dos efeitos dos danos neurológicos e das anomalias, na infância e na vida futura dos bebês afetados. Conclui-se que essa permanência histórica da epidemia de microcefalia e, portanto, da Síndrome Congênita do Zika, não foi adequadamente antecipada pelos jornais que noticiaram o fenômeno naquela época.
\end{abstract}

Palavras-chave: Análise do Discurso; microcefalia; Síndrome Congênita do Zika; narrativa jornalística; história das epidemias.

\section{The "zika children" as Brazilian newspapers told us: a retrospective reading from the news coverage}

\begin{abstract}
:
This study is based on the premise that the Zika epidemic is an unfinished story, as its consequences will extend forever. Such consequences are evident in the sequelae suffered by children affected by the congenital syndrome - people with multiple disabilities, who will continue to demand, from both their families and the State, perennial care. For this reason, I conducted a documentary research that analyzed the narrative regarding the Congenital Zika Syndrome/Microcephaly, presented in the first two and a half years widely read Brazilian newspapers. The focus was to understand how the media discourse regarding the effects of brain damage and anomalies, in childhood and in the future life of affected babies, took place. The results show that the historical permanence of the microcephaly epidemic and, therefore, of the Congenital Zika Syndrome, was not adequately anticipated by the newspapers that reported the phenomenon at that time.
\end{abstract}

Keywords: Discourse analysis; microcephaly; Congenital Zika Syndrome; journalistic narrative; history of epidemics.

\footnotetext{
1 Artigo produto do Estágio Pós-Doutoral realizado no Programa de Pós-Graduação em Informação e Comunicação em Saúde (PPGICS), do Instituto de Comunicação e Informação Científica e Tecnológica em Saúde (Icict), da Fundação Oswaldo Cruz.

${ }^{2}$ Sanitarista e Doutora em Antropologia. Professora Associada do Programa de Pós-Graduação em Educação e do Programa de Ensino, Filosofia e História das Ciências da Universidade Federal da Bahia. Agradeço ao financiamento do CNPq - Processo n.438716/2018-3. E-mail: alssb66@gmail.com.
} 


\title{
Los "niños del zika" según nos dijeron los periódicos brasileños: un análisis retrospectivo de la cobertura de los medios
}

\begin{abstract}
Resumen:
Este estudio se basa en la premisa de que la epidemia de Zika es una historia inconclusa, ya que sus consecuencias se extenderán para siempre. Están estampadas en las secuelas que sufren los niños afectados por el síndrome congénito, personas con múltiples discapacidades, que seguirán exigiendo, tanto a sus familias como al Estado, cuidados perennes. De esta forma, se realizó una investigación documental que analizó la narrativa sobre el Síndrome de Zika Congénito/Microcefalia, recortada durante los primeros dos años y medio de cobertura noticiosa em periódicos brasileños amplamente leídos. El objetivo fue comprender cómo se desarrolló el discurso mediático sobre los efectos del daño cerebral y las anomalías, en la infancia y en la vida futura de los bebés afectados. Se concluye que esta permanencia histórica de la epidemia de microcefalia y, por tanto, del Síndrome Congénito del Zika, no fue anticipada adecuadamente por los periódicos que informaron del fenómeno en ese momento.
\end{abstract}

Palabras clave: Análisis del Discurso; microcefalia; Síndrome de Zika Congénito; narrativa periodística; historia epidémica.

\section{Introdução}

A história da epidemia de zika é uma história inacabada. Refletir sobre sua permanência levou Diniz e Brito (2018, p. 169) a nomeá-la como "Epidemia sem fim”. Nesses termos, os términos das emergências em saúde pública evidenciaram insensibilidade ao sofrimento das mulheres contaminadas pelo vírus da zika, que tiveram suas vidas radicalmente transformadas após o nascimento das crianças.

Ouvir falar sobre essas crianças hoje em dia e saber de suas deficiências tão graves nos mobiliza tanto pela dramaticidade do fato em si, quanto por uma estranha sensação de tardio reconhecimento, para o qual nos mostrávamos incautos. As "crianças da zika", boa parte atualmente com cinco anos, se fizeram visíveis ao alcance de todos. Nos tempos pré-pandemia era possível notá-las circulando por cidades do Nordeste nos ombros das suas mães e, dependendo da qualidade das calçadas, em carrinhos de bebê ou já em pequenas cadeiras de rodas. Ali estavam - "mães de micro" e seus filhos - a caminho de sessões de fisioterapia, de farmácias populares para receberem insumos e medicações ou indo e voltando de escritórios da filantropia governamental de onde esperavam garantir benefícios assistenciais. Cumpriam itinerários terapêuticos, descritos pela literatura antropológica que etnografou essas mães (FLEISCHER, 2017), como périplos complexos que, dentre outras coisas, expunham essas crianças à apreciação do cidadão comum. 
No primeiro ano da epidemia, a exposição midiática das mães e dos bebês era intensa, como destacado no trabalho de Araújo e Aguiar (2017, p.16). Mas o passar do tempo, a redução do número de nascimentos de crianças com as anomalias e a saturação da opinião pública com a cotidianidade das nossas tragédias nacionais foi esvaziando as "crianças da zika" da pauta dos noticiários. Então, a "pandemia do corona", que as tirara da apreciação visível das ruas, as recolocou de volta aos noticiários para nos mostrar seus riscos aumentados de adoecimento e morte na condição de grupo vulnerável à infecção. Logo, pudemos novamente observá-las. Elas haviam crescido bastante. Então pudemos ver que elas não conseguiam se sentar sozinhas, equilibrar o pescoço, abrir e fechar as mãos para segurar algo.

Há um bom tempo as "crianças da zika" tem estado disponíveis para a constatação inequívoca de que são pequenas pessoas com deficiência. Elas não falam ou o fazem com dificuldade importante de articulação das palavras. São crianças que, nas expressões mais severas (e relativamente comuns) do dano cerebral que as acometeu, são incapazes de comer sozinhas, mal mastigam e engolem o alimento (WHEELER, 2018).

Para algumas, nem mesmo a mamadeira lhes adianta. Então, fazem uso de sondas que levam a comida para dentro de suas barrigas, entrando pelo nariz ou por um orifício feito na altura do estômago. ${ }^{3}$ Não raro, são assim fotografadas por suas famílias, que fazem circular, nas redes de relacionamento das mídias sociais, registros dos seus cotidianos.

Uma parcela importante dessas crianças sofre com convulsões de difícil controle. As que são medicáveis a contento se fazem ao preço, muitas vezes, de letargia e sonolência, comumente visíveis às fotos, também. Muitas possuem, ainda, atrasos na inteligência, se comparadas com outras crianças da mesma idade, bem como possuem distúrbios sensoriais que lhes dificultam enxergar ou ouvir. Muitas delas, além de identificáveis pelas deformidades em braços e pernas, possuem, é claro, a icônica microcefalia.

Entretanto, por mais que agora se mostre óbvio, e por mais correntes que sejam hoje as referências - nos documentos oficiais, no noticiário da televisão, nas matérias de jornais - à deficiência das "crianças da zika", não parece ter sido assim desde o começo. Pelo menos não direta ou imediatamente apreensível ao nosso entendimento. Olhando para trás, fica a impressão

\footnotetext{
${ }^{3}$ A respeito das gravidades instaladas que desenham um quadro de múltiplas incapacidades, extrema dependência e necessidade de cuidados intensos para uma parte expressiva das crianças acometidas pela Síndrome Congênita do Zika, ver: Ventura, Lage, Carvalho, Fernandes, Taguchi e Nascimento-Carvalho (2020).
} 
de que não tinham nos contado corretamente como ficariam os bebês da zika. Não para o cidadão comum, aquele que, no início, só conhecia o problema pelas notícias na mídia.

Assim sendo, interessou saber o que os jornais brasileiros disseram acerca do desenvolvimento infantil sob o efeito das sequelas do zika vírus. E se, ao fazê-lo, esses jornais ajudaram seus leitores a entender que aquelas crianças seriam bastante diferentes das demais, para além de crescerem com uma cabeça muito menor.

Não seria a primeira vez que os jornais brasileiros nos contariam sobre surtos de doenças e/ou desastres sanitários que fazem aparecer deformidades nos filhos de mães contaminadas. Retroagir no tempo faz enxergar dois episódios paradigmáticos. Um deles foi o surto de rubéola que atingiu mulheres grávidas, cujos filhos nasceram surdo-cegos e/ou com deficiência mental. O outro foi o consumo do medicamento teratogênico Talidomida por mulheres gestantes, cujos filhos nasceram sem membros.

Historiadores da Ciência, como Löwy (2019, p. 117), traçaram interessantes paralelos entre a epidemia de zika e o surto de rubéola no Brasil, na medida em que ambos motivaram a realização de abortos. A própria mídia impressa reconheceu essa aproximação. Em matéria do jornal Estadão, intitulada "Microcefalia e aborto: debate não começou com zika", a repórter (BATISTA, 2016) faz constar que "Na década de 1970 surto de rubéola aqueceu discussão sobre a liberação do aborto preventivo", e nesse intento reproduz diversos recortes de jornais daquela época.

Caso olhemos para a Talidomida, vale destacar que a produção intelectual das Ciências Sociais brasileira problematizou a questão, inclusive a partir de fonte documental proveniente de cobertura da imprensa que fez circular notícias na época do evento. Foi o caso, por exemplo, de Leandro e Santos (2015), que trabalharam com jornais editados no Rio de Janeiro entre 1959 e 1962, e de Moro e Invernizzi (2017), que exploraram a discussão dos casos de infanticídio de crianças com as malformações, largamente debatidas nas páginas de jornais nacionais e estrangeiros.

\section{Procedimentos metodológicos}

Responder à pergunta que orientou a investigação aqui relatada requereu uma leitura e interpretação sociolinguística da cobertura noticiosa sobre a síndrome congênita do zika, com 
especial atenção à narrativa construída sobre os bebês e as crianças afetadas. Esse empreendimento se realizou através de análises semióticas ancoradas na Escola Francesa de Análise de Discurso atualizadas, por sua vez, em trabalhos que sugerem operacionalizações bastante práticas, como o de Charaudeau (2006) e o de Gill (2002).

Para compor o corpus empírico foram buscados os acervos dos jornais Folha de $S$. Paulo, Estadão, O Globo e Jornal do Commercio, assim como notícias eventuais publicadas em A Tarde, de Salvador, Correio Braziliense, Jornal Zero Hora e A Tribuna da Paraíba. Foi recortado o período de outubro de 2015 a dezembro de 2017, perfazendo um total de 27 meses. A amostra continha artigos, editoriais, matérias e reportagens que discorriam sobre a Microcefalia/Síndrome Congênita do Zika. O montante final reuniu 218 unidades para análise. A distribuição proporcional de cada veículo de comunicação na composição da amostra consta no Gráfico 1, abaixo.

Gráfico 1 - Participação dos principais jornais de circulação nacional na cobertura noticiosa da Síndrome Congênita do Zika Vírus - outubro/2015 a novembro/2017

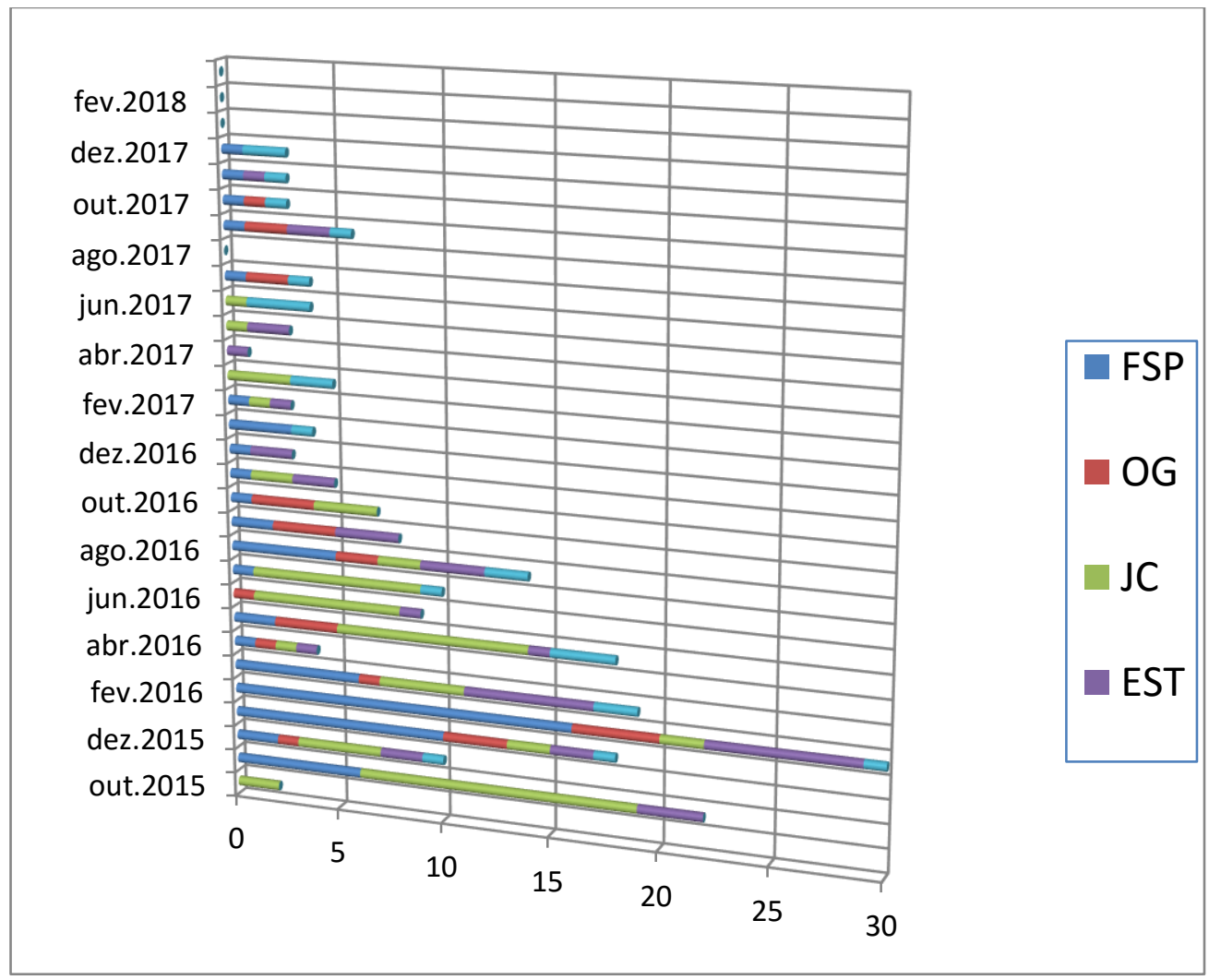

Fonte: a autora. 
Quarenta categorias descritivas auxiliaram na interpretação dos discursos subjacentes às notícias de jornal, executada à custa de leitura atenta e escrutinada das duzentas e dezoito unidades da amostra procurando registrar a frequência dos descritores assinalados, assim como suas múltiplas interrelações. Esse esquadrinhamento se debruçou sobre cada uma das matérias individualmente, como também por sobre a coleção reunida das duzentas e dezoito. Tal expediente favoreceu acompanhar disputas de sentido em torno dos temas que emergiam, assim como o adensamento argumentativo que ganhava mais tessitura na medida em que notícias anteriores somavam significado às enunciações das seguintes.

O trânsito narrativo entre um e outro jornais, que ora reproduziam quase que textualmente o discurso do veículo concorrente e ora rompiam a mesmice repetitiva da cobertura trazendo informação diferencial, foi melhor capturado por essa apreensão ampliada da grande coleção das 218 matérias de jornal. Mas esse jogo gestáltico da parte e do todo exigiu também que se considerasse cada matéria individualmente no plano maior do conjunto amostral. Portanto, a "cobertura noticiosa", cujo senso de unidade foi dado pelo recorte temporal e pela circunscrição do assunto - microcefalia e síndrome congênita do zika - era composta pelo grupamento anônimo do corpus e, ao mesmo tempo, pela singularidade de matérias com sentidos próprios.

A análise linguística apreciou a gramática que ordenou as ideias nos textos de jornal e os estratagemas pragmáticos para convencimento do leitor. Foram identificados termos, expressões do vocabulário, jargões, figuras de linguagem e outros operadores de significado utilizados na escrita, como referência às expectativas em relação ao desenvolvimento de bebês com microcefalia ou afetados pela síndrome congênita. $\mathrm{O}$ mesmo se deu na leitura dos recursos semânticos - ilustrações, ênfases em informações, status de autoridade do informante nas enunciações. O exercício de interpretação foi um diálogo entre um nível mais evidente, que buscava informações explícitas, e outro mais sutil, apostando em significados silenciosos e estratégias retóricas contidas nas mensagens das notícias de jornais.

O registro da regularidade dessas estruturas narrativas, assim como da presença dos descritores, ofereceu alguma medida do efeito de esclarecimento comunicado pelos jornais 
sobre a vida futura das "crianças da zika". O Gráfico 2 ilustra parte dos achados brutos, depurados posteriormente na interpretação e acionados para justificar os resultados.

Gráfico 2 - Distribuição de categorias descritivas da análise de discurso dos jornais - cobertura da Síndrome Congênita do Zika

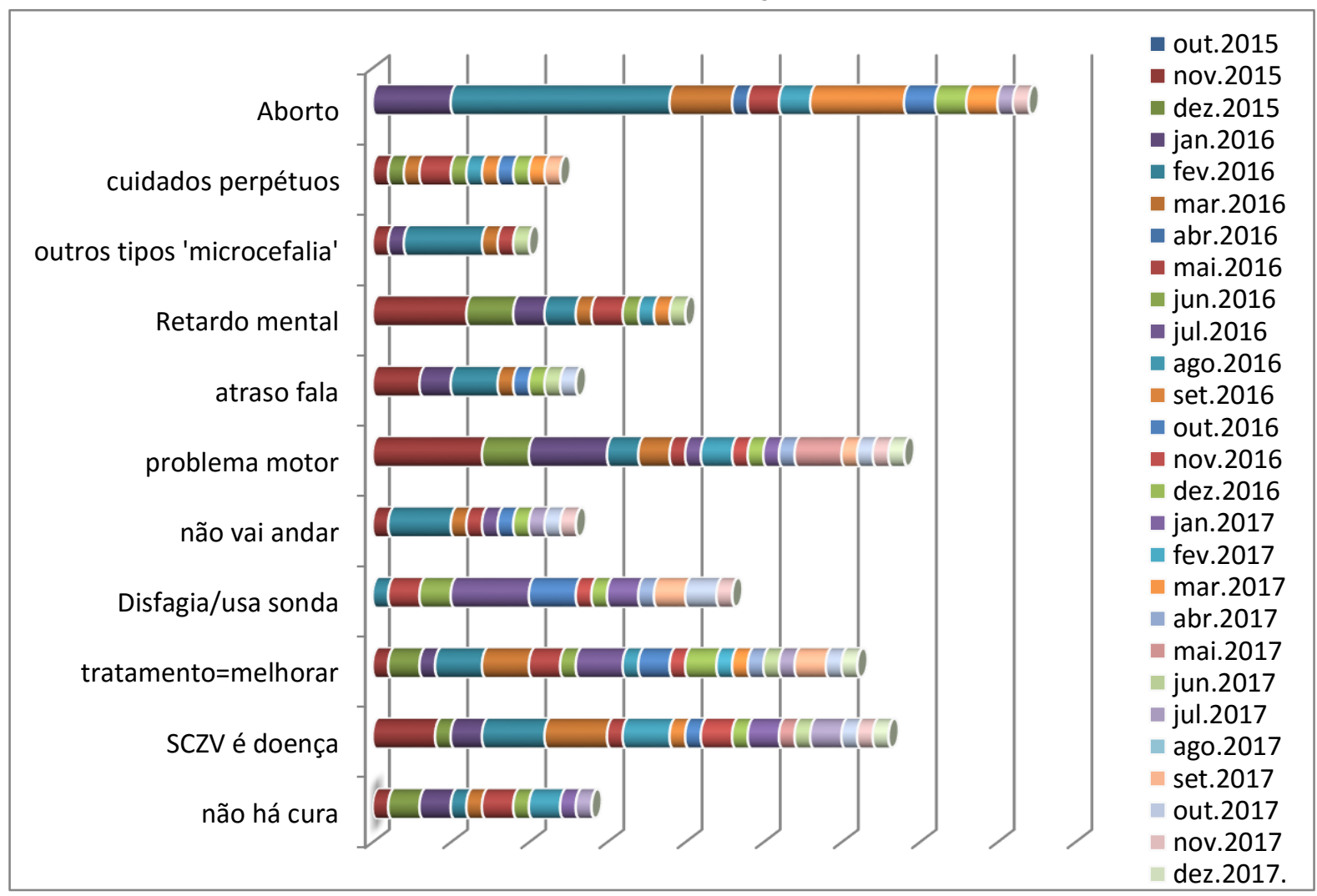

Fonte: a autora.

Por fim, procedeu-se à avaliação crítica dos achados, circunstanciada pelo contexto socio-histórico e momento político do período datado. O Diagrama 1 ilustra uma "linha do tempo" sequenciada ao longo dos meses da cobertura recortada, que organizou, na forma de tópicos e temas, as principais notícias acerca da Microcefalia/Síndrome Congênita do Zika, veiculadas pela mídia impressa. 
Diagrama 1 - Linha do tempo: percurso temático de eventos relacionados ao noticiamento da Síndrome Congênita do Zika pelos jornais brasileiros

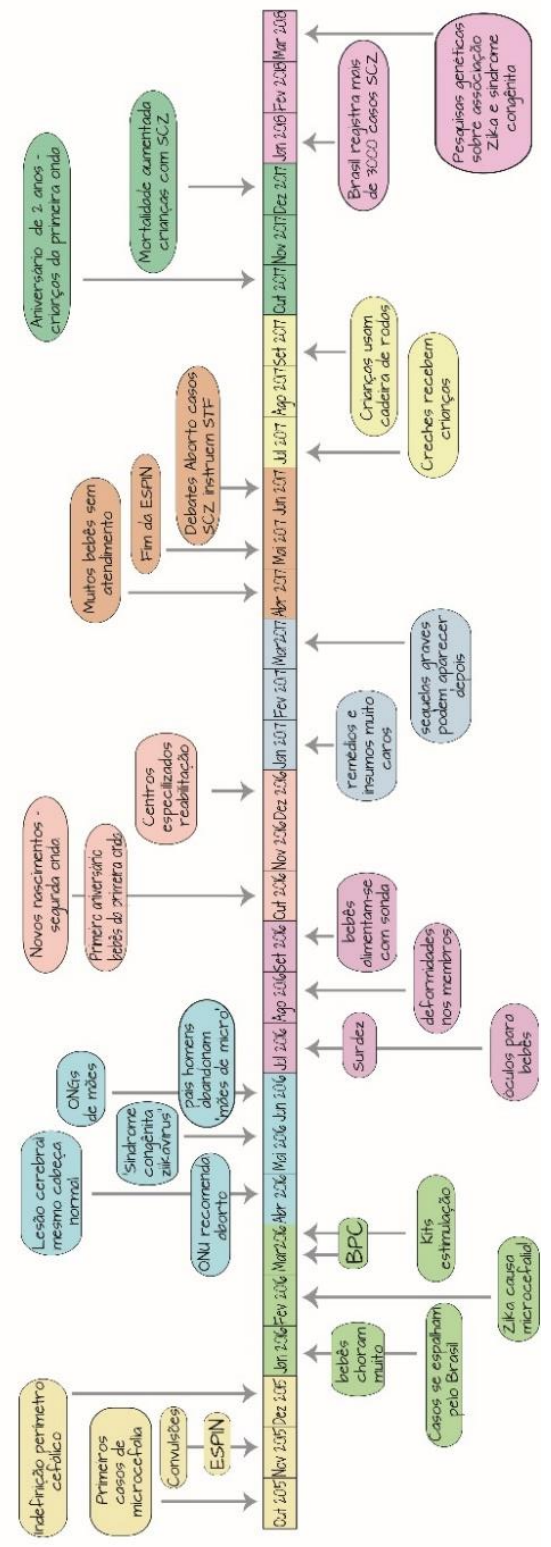

Fonte: a autora.

O testemunho e o legado dos jornais acerca da infância vindoura das "crianças da zika"

Os resultados dissertados nesta seção estão nomeados pelo ano em que se deram. São relatos que buscaram articular de modo lógico e interpretativo os múltiplos eventos, episódios, 
ocorrências, manifestações oficiais, associados ao fenômeno epidêmico, os quais, noticiados nos jornais, levavam o leitor a pensar como ficariam as "crianças da zika".

\section{Ano de dois mil e quinze}

Foi a microcefalia quem despertou a atenção de obstetras e neonatologistas de que um grave problema de saúde pública pairava no estado do Pernambuco. A zika viria logo em seguida: de início, como suspeita, e, depois, como culpada efetiva pelos nascimentos das tantas crianças com as cabeças muito pequenas. Mas, no começo de tudo, foi ela, a microcefalia, a grande protagonista. ${ }^{4}$ Uma entidade que, sozinha, parecia dizer tudo e que, compondo a chamada das matérias, aparecia como a primeiríssima palavra em mais da metade das manchetes e seus leads.

O ano de 2015 nos falava, ainda, de uma escalada do número de nascimentos de crianças com a anomalia. Mostrava-nos que os casos avançavam pelo Nordeste, rondavam outras regiões do Brasil e se avolumavam com mais rapidez do que se podia imprimir às investigações que apontariam a causa do fenômeno.

Os números eram assunto, também, quando se tratava de saber, afinal, quão pequena seria uma cabeça de recém-nascido para que ali fosse diagnosticada a microcefalia. Num país como o nosso, essa preocupação com tamanhos de cabeças de bebês não era gratuita. Apenas três anos antes havíamos aprendido o que era a "anencefalia" e que fetos assim seriam, por fim, elegíveis para o aborto. Talvez, então, sub-repticiamente já nos antecipávamos às querelas sobre o aborto daqueles novos tipos de fetos - os com microcefalia.

Nos últimos meses de 2015, veremos surgir nos jornais alguns formatos narrativos peculiares para descrever o que acontecia, pois parecia difícil nomear algo tão novo para o cenário midiático. Por isso, a microcefalia foi, paralelamente aos termos "malformação" e "anomalia", outras tantas vezes chamada pelo nome - abstrato e um tanto indefinido - de "condição". Veremos começar, também, com alguma insistência e de um modo que se

\footnotetext{
${ }^{4}$ A esse respeito, ver Ribeiro, Hartley, Nerlich e Jaspal (2018, p.142): "Zika became tangible in a particular manner, as microcephaly became a global symbol of the epidemic". Ver, igualmente, Lima (2020, p.157): “ [...] Sugiro que foi pelas imagens da mídia que todo esse fenômeno passou a ser resumido por um de seus sintomas, a microcefalia".
} 
estenderia por todos os anos de cobertura da amostra, a microcefalia ser chamada, pelos jornais, de "doença", quando, a rigor, doença mesmo seria apenas a zika, a virose.

Esse atrelamento simbólico - da microcefalia como sendo uma "doença" - não se faria inócuo. Porque quando se falava em "doença", estava implicada alguma expectativa de cura. Logo, se a Síndrome do Zika estava sendo tomada, pelo público leitor, por uma doença, deveria haver um modo das crianças ficarem saradas. Mas não havia. Esse fato, em sendo ponto pacífico e óbvio que hoje assim nos pareça, caberia ter sido, e com alguma regularidade, assinalado à época pelos jornais. Mas não o foi. Poucas vezes - em apenas 14 do montante das 218 notícias - era possível ler nos jornais que não havia cura para a microcefalia ou para a Síndrome Congênita do Zika.

Portanto, uma brasileira que parisse um bebê com microcefalia em dezembro de 2015 , e que viesse se informando pelos noticiários, saberia da declaração do Governo de que o país estava em estado de emergência, fosse lá o que isso significasse para ela. De real importância, ela saberia apenas que estava levando para casa um recém-nascido o qual, além da cabeça demasiado pequena, teria muitas convulsões. Isso os jornais já diziam.

Essa mulher teria buscado entender o que mais haveria de diferente em seu bebê: como ele estaria, para além do que se via por fora. Saberia, então, graças aos jornais, que seu filho tinha um "atraso no desenvolvimento". Mas daí a entender, objetivamente, o que isso significaria, uma grande distância se impunha. Pois a ideia de decurso, de processo, embutida no termo "atraso no desenvolvimento", reclama a paciência de ver o tempo passar. Projeta incertezas, mas também esperanças de que, lá adiante, uma mãe possa conferir o que terá sido apenas um ritmo lento na vida de seu filho, o qual, no fim das contas e para alegria dessa mãe, seria equiparado às demais crianças. Os anos que se seguiram mostrariam à grande parte das mães da epidemia de zika que, infelizmente, não seria bem assim.

Alternando entre a vagueza de prognósticos como esses e a dramaticidade de vaticínios trágicos que falavam, por exemplo, em "geração de sequelados", o leitor de jornal dos últimos meses de 2015 se via em meio a explicações neurológicas e estatísticas que pouco lhe diziam de prático acerca do futuro dos bebês com microcefalia.

Eventualmente, algumas notícias traziam declarações de especialistas acerca da gravidade do quadro: "A maior parte dessas crianças tem alterações muito extensas no cérebro. 
[...] com alterações desse tipo, o mais provável é que esses bebês tenham implicações motoras e cognitivas mais importantes" (CANCIAN, 2015). "[Terão] complicações como dificuldade de locomoção, de raciocínio, de fala, de aprendizado, entre outras" (ALVES; MIOTO, 2015). Outras vezes, essa retórica era traduzida, subtraída de circunlóquio e o leitor podia ler, como de fato foi possível em 20 notícias de jornal, que aquelas crianças teriam "retardo mental".

Em 2015 as fotografias que ilustravam as notícias nos mostravam apenas pequenos e graciosos bebês. Alguns registros, contrariamente, notabilizaram-se pelo modo drástico como expuseram a circunferência exageradamente pequena de algumas cabeças de bebês da zika. Mas esse tamanho muito menor nem sempre era visível ou não se fazia destacar em sua miudeza, dada a proporção do resto do corpo, também diminuto e ainda imaturo. Logo, a declaração de um especialista médico sobre a seriedade das complicações sistêmicas que, em breve, iriam se manifestar naquelas crianças, teria que disputar sentidos com o que se via nas imagens das notícias. Ao olhar do leigo era difícil acreditar que aqueles bebês carregavam sérios problemas por dentro.

Além disso, quando os jornais reproduziam o modo como as mães viam seus bebês com microcefalia, notava-se que elas também, de modo muito genuíno e sincero, enxergavam apenas a formosura de seus filhos: "Eu olho para minha filha e vejo uma coisa linda: toda perfeitinha" (COLLUCCI, 2015). "Ele é todo perfeitinho, só a cabeça é pequenininha" (CANCIAN; ANIZELLI, 2015). "Na hora pensei que ele nasceria muito estranho. Mas ele está bem" (FORMENTI, 2015).

\section{Ano de dois mil e dezesseis}

O ano seguinte foi desafiador para os jornais noticiarem a Síndrome do Zika. No início os números cresciam e se espalhavam para além da região Nordeste, o que mantinha o tema sob intenso agendamento. Indagações sobre a maior susceptibilidade de alguns fetos mobilizavam as redações de jornais. Acima de tudo, o ano de 2016 foi de grande turbulência política: a presidenta Dilma sofreu um impeachment, técnica e juridicamente pouco defensável, e o vice Michel Temer assumiu o Governo. Aquele foi também o ano em que a Olimpíada foi sediada no nosso país. 
Embora essas pautas tenham disputado o espaço dos jornais e a atenção do público leitor, elas estimularam a divulgação de notícias sobre a epidemia de microcefalia. Pois as condições sanitárias sob as quais vivem as mulheres nordestinas contaminadas pela zika estavam sendo ideologicamente associadas, pelos partidos de oposição, à administração do Partido dos Trabalhadores (PT). Como bem assinalou Matta, Nogueira, Rabello e Silva (2019), para os adversários da presidenta Dilma, o drama da zika era uma oportunidade no jogo político.

A Olimpíada, por sua vez, era noticiada tanto pela sua importância como evento esportivo internacional, quanto pelo fato de que várias atletas estrangeiras estavam anunciando suas desistências de vir ao Brasil para evitar o risco da contaminação pelo vírus da zika.

No ano de 2016, bastava aos jornalistas acompanhar os "bebês da zika" crescendo, que havia garantia certa de notícia. A imprensa já recebera previsões de neonatologistas de que a síndrome afetaria de forma grave, contínua e extensivamente os recém-nascidos. Portanto, cada mês que se passasse no ano e, por conseguinte, cada mês que se passava na vida daqueles bebês proporcionava algo de novo para um repórter registrar. A mídia cumpriria, assim, um papel de intermediador preferencial entre os prognósticos médicos, as expectativas das famílias afetadas e o entendimento do cidadão comum.

Essa cobertura noticiosa aproximaria as vertentes científicas e investigativas do jornalismo de uma maneira peculiar. Pois naquele ano, como posteriormente nos mostrariam Kelly, Lezaun, Löwy, Matta, Nogueira e Rabello (2020), muito desconhecimento acerca da nova anomalia ainda se impunha como prioridade para ser desvendado, pelos pesquisadores, e depurado do jargão médico e reportado ao leitor, pelos jornalistas. Nesse sentido, a explicitação das dúvidas, a cobrança por respostas, o confrontamento com explicações alternativas e a tentativa de encadeamento lógico dos achados no fluxo de comunicação faria dos jornais, como assinalou Diniz (2016), porta-vozes da curiosidade do grande público, interessado em entender os efeitos das sequelas e saber como ficariam os bebês da zika quando crescessem.

Muita coisa já se sabia: aquelas crianças também teriam sérios problemas de visão, de audição, deformidades em braços e pernas ao ponto em que a ciência asseverou que a questão estava muito além de uma cabeça e um cérebro pequenos. Tratava-se, efetivamente, de um quadro mais complexo: uma síndrome. E mesmo crianças com cabeças de proporções normais poderiam, secundariamente à infecção pré-natal por zika, estar sofrendo consequências e, 
portanto, carregarem a dita síndrome. Isso tudo foi, repetidas vezes, noticiado ao longo dos meses do ano. A partir de 2016 (e se estendendo por 2017), o tema do "aborto", endereçado às gravidezes contaminadas pela zika, seria retratado em 42 das 218 matérias da amostra analisada. ${ }^{5}$

Ao mesmo tempo em que se acumulava o detalhamento sobre os pormenores complicadores da síndrome, os jornais pareciam sugerir que a microcefalia, na vida futura da pessoa acometida, não representaria um veredicto de tão grande gravidade. Com alguma regularidade, publicaram notícias de adolescentes e jovens adultos vivendo com relativa autonomia, apesar de suas microcefalias. Eram outros tipos de anomalia craniana que cumpriam o papel de associar positivamente a microcefalia a formas adultas de vida independente, isentas de comorbidades. Nenhuma das pessoas que ilustrou aquelas matérias estava em cadeira de rodas ou parecia usar fraldas, por exemplo. A mensagem ao leitor dos jornais era de que os problemas de desenvolvimento implicados pela Síndrome Congênita do Zika não seriam no futuro, afinal, tão sérios.

Os jornais de 2016, embora ainda muito ocupados pela epidemia, produziram uma cobertura noticiosa em que não se falava propriamente das crianças acometidas. Pouco se dizia, de modo traduzido e inteligível, dos impactos da zika congênita na expressão mais básica de ser um bebê que segue crescendo e fazendo - ou não - coisas triviais. Por mais reproduzida que a síndrome fosse - em suas nuanças, exceções e regularidades - esse detalhamento explicativo parecia atrelado a um grande conceito definidor: - "síndrome", que nomeava, mas não explicava ilustradamente o que se passava com as crianças que dela sofriam.

Assim, terminaríamos o ano vendo as crianças da zika comemorarem um primeiro aniversário; mas fazê-lo, pelo que as fotos na imprensa deixavam enxergar, ainda recostadas no colo de suas mães. Instruídos por aquilo que a mídia nos permitiu saber, achamos, provavelmente, que se elas ainda não andavam poderiam vir a caminhar no ano seguinte. Embalados por essa expectativa, não nos demos conta - e os jornais não nos ajudaram a entender - que nem mesmo sentar sozinhas aquelas crianças de um ano de idade eram capazes.

\footnotetext{
${ }^{5}$ Embora aos propósitos da pesquisa que orientou este artigo não interessasse imediatamente a questão do aborto, suas implicações no modo como a Microcefalia/Síndrome Congênita foi tratada discursivamente pelos jornais não podem ser ignoradas. A esse respeito recomendo o trabalho de Gressick, Gelpi e Chanroo (2019) e o de Castilhos e Almeida (2020).
} 


\section{Ano de dois mil e dezessete}

A cobertura do ano seguinte nos dava a boa notícia de que a taxa de nascimentos de bebês com a síndrome caíra. A má notícia era que as crianças não vinham recebendo o atendimento esperado. Havia dificuldade de acesso aos centros de reabilitação, inoperância dos serviços, inadequação da rede de assistência primária em saúde.

Esse enfoque narrativo fazia parecer que as crianças não melhoravam porque não estavam recebendo tratamento adequado. De fato, não estavam, não como mereceriam enquanto sujeitos de direito. Mas o dito "tratamento" que efetivamente se destina a crianças como as "da zika" é reabilitativo e não curativo. Essa sutil diferença nunca haveria de ficar devidamente esclarecida para o leitor, que vinha nos anos anteriores, e assim prosseguiria por 2017, vendo o tema do "tratamento" ser assinalado repetidamente pelos jornais: em 32 matérias, dentre as 218 da amostra.

Nesses termos, o que a mídia ajudara a criar em torno da palavra "tratamento" era a ideia de que "quanto mais melhor". E se essa compreensão se fazia possível, era porque pouco, ou quase nada, havia sido dito pelos jornais sobre o alcance concreto e as reais possibilidades de melhora depositáveis na tão citada "estimulação precoce". Pois ela, embora recorrente ao longo dos três anos da cobertura noticiosa analisada - presente em 40 das 218 matérias - não seria tratada com a lucidez necessária.

Do mesmo modo, o que se vinha lendo sobre as crianças da zika até então, e assim prosseguiria ao longo de 2017, eram definições pontuais e revestidas do tecnicismo médico. Menções ao termo "comprometimento motor" se destacaram pela quantidade em que apareceram: em 31 das 218 notícias de jornal analisadas. Mas pouquíssimas vezes - onze dentre as 218 - os jornais se expressaram em termos coloquiais fazendo uso simplesmente da expressão "não andar".

Logo, dificilmente um leitor usual de jornal poderia presumir que, no fim das contas, muitos dos "filhos da zika", mesmo submetidos à estimulação e ao tratamento reabilitativo, chegariam aos dois anos sem equilibrar o próprio tronco e sem abrir e fechar as mãos. Uma ou outra notícia the diria, efetivamente, que a criança "ainda não sustenta a cabeça" (SOTERO, 
2017), "não sustenta o pescoço" (MARQUES, 2017) ou que, com vinte e quatro meses de vida, “ele não senta, não rola, não consegue segurar um brinquedo" (CAMBRICOLI, 2017).

Portanto, se esse leitor dependesse do sentido construído coletivamente pela cobertura noticiosa de vários jornais, seria levado a crer que, se as "crianças da zika", aos dois anos de idade ainda estavam sem andar, era talvez uma questão de continuar esperando um pouco mais. E, assim sendo, somente quando muita demora deixasse de se mostrar razoável, dada a idade avançada da criança, ali se decretaria uma sequela definitiva. Hoje sabemos: boa parte delas não andou e nunca andará. ${ }^{6}$

Ao final do ano de 2017, as sequelas instaladas nas crianças, que contraíram a zika de suas mães, pareciam ter se estabelecido em suas vidas. Representavam, para muitas delas, dificuldades evidentes em equilibrar o pescoço, sentar sem apoio, engolir alimentos, segurar objetos. Eram atrasos no desenvolvimento que persistiam desde os anos iniciais de suas vidas e que, passado o tempo, atualizavam-se em subsequentes dificuldades para caminhar, para falar, para compreender o mundo ao seu redor. Mas, por mais evidente que fosse essa realidade, apenas duas matérias, ao longo desse terceiro ano de cobertura, falaram do uso de "cadeira de rodas", quando discorrendo sobre as necessidades no cotidiano de cuidados das crianças da zika.

Quando, para fins de arremate analítico, aprecia-se o conjunto ampliado das notícias veiculadas ao longo dos anos de 2015, 2016 e 2017, constata-se que em apenas 15 matérias das 218 se pode ler textualmente menções à "deficiência" expressamente associadas à "criança da zika". Assim também, acompanhando esse mesmo estilo narrativo da cobertura noticiosa, constatou-se que igualmente esparsas - nove em meio às 218 - foram as menções à exigência de cuidados que se estenderia, de modo indispensável e perene, pelas vidas da maioria daquelas crianças.

\footnotetext{
${ }^{6}$ Com o passar dos anos, vários artigos científicos sobre a Síndrome da Zika atestariam os prognósticos pouco promissores para as crianças afetadas (PEREIRA, SANTOS, AMÂNCIO, OLIVEIRA-SZEJNFELD, FLOR, TAVARES, FERREIRA, TOVAR-MOLL, AMORIM e MELO, 2020), que muitos médicos e pesquisadores já anunciavam antes, quando entrevistados pelos jornais.
} 


\section{Considerações finais}

A zika foi uma epidemia vivida na concomitância de seu vigoroso noticiamento pela mídia. A periodicidade resultante da circulação regular das notícias fez com que os jornais cumprissem um papel de "arquivos do cotidiano" (ZICMAN, 1985, p. 90), registrando a memória da síndrome congênita e permitindo estabelecer uma cronologia dos fatos históricos a ela associados. Sua cobertura noticiosa ajudou a construir os contornos do fenômeno, tanto quanto o fizeram os indicadores estatísticos dos boletins epidemiológicos e as publicações científicas.

A análise aqui apresentada nos mostrou que os jornais pouco disseram sobre como as crianças acometidas ficariam. A narrativa jornalística sobre a síndrome do zika também não deixou suficientemente claro que os bebês acometidos não poderiam ser curados e, assim sendo, não favoreceu a compreensão de que eles seriam, em sua maioria, crianças com deficiências múltiplas e graves.

Histórias semelhantes já haviam sido contadas pela imprensa brasileira, por meio das notícias dos surtos de rubéola e de Talidomida, em meados do século vinte. Os leitores de então se puseram a entender os efeitos nas crianças nascidas à custa de um repertório de adjetivos que incluía termos como "monstruosidade", "deformados", "aleijados", conforme observável em estudos que compilaram notícias da época, como o de Leandro e Santos (2015) e o de Moro e Invernizzi (2017).

As preocupações éticas do jornalismo atual com o tratamento da linguagem usada para se referir à diferença identitária e o consequente cuidado na escolha das palavras nos distanciaram progressivamente daquelas representações estigmatizantes. ${ }^{7}$ Esse cuidado, inegavelmente importante, expressão do respeito à dignidade humana, talvez esteja se desdobrando num zelo maior que vem levando a um certo silenciamento sobre a concretude

\footnotetext{
${ }^{7}$ A perspectiva dos meios de comunicação acerca da abordagem mais adequada para informar o público sobre as epidemias de zika e de microcefalia foi discutida por jornalistas que estiveram na linha de frente da cobertura, assinando matérias do Estadão, do Jornal do Commércio, da Folha de S. Paulo. Suas opiniões e resgates históricos do processo estão disponíveis em Formenti (2017), Leite (2017) e Collucci (2018).
} 
objetiva da deficiência, a qual, no caso das crianças da zika, inexoravelmente se estabelecia em suas vidas. $^{8}$

Contar a história de uma epidemia, cujas consequências ainda estão em curso, seja pela persistência das transmissões, seja pela evidência dos graves efeitos neurológicos nos corpos das crianças em crescimento, passa por reconhecer que ela será uma narrativa provisória. Nos termos de Löwy (2019, p. 13), “Escrever a 'história' do presente dessa epidemia é uma tarefa muito desafiadora porque a compreensão do zika muda o tempo todo, assim como a interpretação de eventos passados".

Contar essa história passou por reconhecer que não apenas uma epidemia em si, como também o conhecimento acumulado em torno dela pode ser tratado como alvo de interesse. Implicou também reconhecer que epidemias, como a de zika e de microcefalia, devem ser escritas tentando desvelar as camadas de silenciamentos que os discursos - oficiais, acadêmicos e midiáticos - por sobre ela se impuseram.

Isto posto, cabe finalizar ressalvando que o exercício de análise aplicado por sobre o conjunto das notícias, recortadas do universo da cobertura jornalística da Síndrome Congênita do Zika, não encerrou resultados epistemologicamente isentos. O conhecimento produzido pela interpretação hermenêutica deverá ser circunstanciado à luz das condições de possibilidade de informar que os meios de comunicação pretendem, bem como aos limites da apreensão sensível que a linguística e a pesquisa em ciências sociais comportam.

\section{Referências}

ALVES, Gabriel; MIOTO, Ricardo. A ciência do Zika. Folha de S. Paulo, São Paulo, 25 nov. 2015. Ciência \& Saúde.

ARAÚJO, Inesita Soares; AGUIAR, Raquel. O vírus Zika e a circulação dos sentidos: entre limites e ressonâncias, apontamentos para uma pauta de pesquisa. In: CASTRO, Paulo César (org.). A circulação discursiva: entre produção e reconhecimento. Maceió: EDUFAL, 2017. v.1, p.141-162.

\footnotetext{
${ }^{8}$ Fenômeno de encobrimento semelhante foi relatado em estudo (BARROS, 2021) que avaliou a reflexão antropológica por sobre a Síndrome da Zika presente em artigos científicos e em trabalhos acadêmicos da autoria de pesquisadores brasileiros.
} 
BARROS, Alessandra Santana Soares. Deficiência, Síndrome Congênita do Zika e produção de conhecimento pela Antropologia. Revista Scientia, Salvador, v. 6, n. 1, p. 142-163, jan./abr. 2021. Disponível em: https://revistas.uneb.br/index.php/scientia/article/view/9292. Acesso em: 21 jun. 2021.

BATISTA, Liz. Microcefalia e aborto: debate não começou com a zika. Estadão, São Paulo, 17 fev. 2016.

CAMBRICOLI, Fabiana. Terapia de estimulação não chega a um terço de bebês com microcefalia. Estadão, São Paulo, 15 abr. 2017.

CANCIAN, Natália. Microcefalia está com novo padrão, dizem especialistas. Folha de S. Paulo, São Paulo, 28 nov. 2015.

CANCIAN, Natália; ANIZELLI, Eduardo. Pensei que fosse efeito de algo que comi, diz mãe de bebê com microcefalia. Folha de S. Paulo, São Paulo, 18 nov. 2015.

CASTILHOS, Washington; ALMEIDA, Carla. Discursos sobre o aborto na epidemia de Zika: análise da cobertura dos jornais $O$ Globo e Folha de S. Paulo. Cad. Saúde Pública, n. 36, Supl. $1,2020$.

CHARAUDEAU, Patrick. Discurso das mídias. São Paulo: Contexto, 2006.

COLLUCCI, Cláudia. Por que não comigo? Folha de S. Paulo, São Paulo, 04 dez. 2015.

COLLUCCI, Cláudia. Dificuldades e desafios na cobertura das epidemias causadas pelo Aedes. In: FUNDAÇÃO OSWALDO CRUZ. Aedes aegypti: vetor de epidemias anunciadas. Brasília, DF: FIOCRUZ/Gerência Regional de Brasília, 2018. p. 48-51.

DINIZ, Debora. Zika: do sertão nordestino à ameaça global. Rio de Janeiro: Civilização Brasileira, 2016.

DINIZ, Debora; BRITO, Luciana. Uma epidemia sem fim: zika e mulheres. In: RIFIOTIS, Theophilos; SEGATA, Jean (org.). Políticas etnográficas no campo da moral. Porto Alegre: UFRGS/ABA Publicações, 2018. p. 169-182.

FLEISCHER, Soraya. Segurar, caminhar e falar: notas etnográficas sobre a experiência de uma "mãe de micro" no Recife/PE. Cadernos de Gênero e Diversidade, v. 3, n. 02, p. 93-112, maio/ago. 2017.

FORMENTI, Lígia. Surto de microcefalia em bebês faz país decretar Emergência Sanitária Nacional. Estadão, São Paulo, 11 nov. 2015. 
FORMENTI, Lígia. Microcefalia, Zika e informação. In: Brasil. Ministério da Saúde. Secretaria de Vigilância em Saúde. Vírus Zika no Brasil: a resposta do SUS/Ministério da Saúde, Secretaria de Vigilância em Saúde. Brasília: Ministério da Saúde, 2017. p. 43-46.

GILL, Rosalind. Análise de Discurso. In: BAUER, Martin; GASKELL, George. Pesquisa qualitativa com texto, imagem e som: um manual prático. Petrópolis, RJ: Vozes, 2002. p. 244 270 .

GRESSICK, Kimberly; GELPI, Adriane; CHANROO, Toni. Zika and abortion in Brazilian newspapers: how a new outbreak revived an old debate on reproductive rights. Sex Reprod Health Matters, v. 27, n. 2, May 2019.

KELLY, Ann; LEZAUN, Javier; LÖWY, Ilana; MATTA, Gustavo Corrêa; NOGUEIRA, Oliveira Carolina; RABELLO, Elaine Teixeira. Uncertainty in times of medical emergency: Knowledge gaps and structural ignorance during the Brazilian Zika crisis. Social Science \& Medicine, v. 246, n. 112787, 2020.

LEANDRO, José Augusto; SANTOS, Francieli Lunelli. História da Talidomida no Brasil a partir da mídia impressa (1959-1962). Saude Soc., São Paulo, v. 24, n. 3, p. 9911005, set. 2015.

LEITE, Cynthia. O olhar cuidadoso do jornalismo em saúde. In: Brasil. Ministério da Saúde. Secretaria de Vigilância em Saúde. Vírus Zika no Brasil: a resposta do SUS/Ministério da Saúde, Secretaria de Vigilância em Saúde. Brasília: Ministério da Saúde, 2017. p. 51-54.

LIMA, Flávia. Mídias. In: FLEISCHER, Soraya; LIMA, Flávia (org.) Micro: contribuições da Antropologia. Brasília, DF: Athalaia, 2020. p. 151-164.

LÖWY, Ilana. Zika no Brasil: história recente de uma epidemia. Rio de Janeiro: Editora FIOCRUZ, 2019.

MARQUES, Marília. Zika: dois anos após epidemia no país, veja como estão bebês com microcefalia. O Globo, Rio de Janeiro, 01 out. 2017.

MATTA, Gustavo Corrêa; NOGUEIRA, Carolina de Oliveira; RABELLO, Elaine Teixeira; SILVA, Lenir Nascimento. Zika outbreak in Brazil: in times of political and scientific uncertainties mosquitoes can be stronger than a country. In: LYNTERIS, Christos (Ed.) Framing animals as epidemic villains histories of non-human disease vectors. Medicine and Biomedical Sciences in Modern History. Switzerland: Palgrave Macmillan; Springer, 2019. p. 211-227.

MORO, Adriana; INVERNIZZI, Noela. A tragédia da Talidomida: a luta pelos direitos das vítimas e por melhor regulação de medicamentos. Hist. Cienc. Saúde-Manguinhos, Rio de Janeiro, v. 24, n. 3, p. 603-622, set. 2017. 
PEREIRA, Heloísa Viscaino Fernandes Souza; SANTOS, Stella Pinto; AMÂNCIO, Ana Paula Rodrigues Lazzari; OLIVEIRA-SZEJNFELD, Patrícia Soares; FLOR, Edneusa Oliveira; TAVARES, Jousilene Sales, FERREIRA, Rayssa Vieira Brandão; TOVAR-MOLL, Fernanda; AMORIM, Melania Maria Ramos; MELO, Adriana. Neurological outcomes of congenital Zika syndrome in toddlers and preschoolers: a case series. Lancet Child Adolesc Health.; v. 4, n. 5, p. 378-387, May 2020. Disponível em: https://www.thelancet.com/action/showPdf?pii=S23524642\%2820\%2930041-9. Acesso em: 21 jun. 2021.

RIBEIRO, Barbara; HARTLEY, Sarah; NERLICH, Brigitte; JASPAL, Rusi. Media coverage of the Zika crisis in Brazil: the construction of a 'war' frame that masked social and gender inequalities. Soc. Sci. Med., p. 137-144, Mar. 2018.

SOTERO, Anderson. Crianças com microcefalia completam dois anos de desafios. A Tarde, Salvador, 01 out. 2017.

VENTURA, Paloma; LAGE, Maria-Lúcia; CARVALHO, Alessandra; FERNANDES, Adriana; TAGUCHI, Tânia; NASCIMENTO-CARVALHO, Cristiana. Early gross motor development among brazilian children with microcephaly born right after Zika Virus infection outbreak. J. Dev. Behav. Pediatr. Wolters Kluwer Health, Inc. v. 42, n. 2. p. 134-140, 2020.

WHEELER, Anne. Development of infants with Congenital Zika Syndrome: what do we know and what can we expect? Pediatrics, v. 141, n. s2, p.S154-S160, fev. 2018.

ZICMAN, Reneé Barata. História através da imprensa: algumas considerações metodológicas. Projeto História, São Paulo, n. 4, p. 89-102, jun. 1985.

Submetido em: 03.10.2020.

Aprovado em: 16.01.2021. 